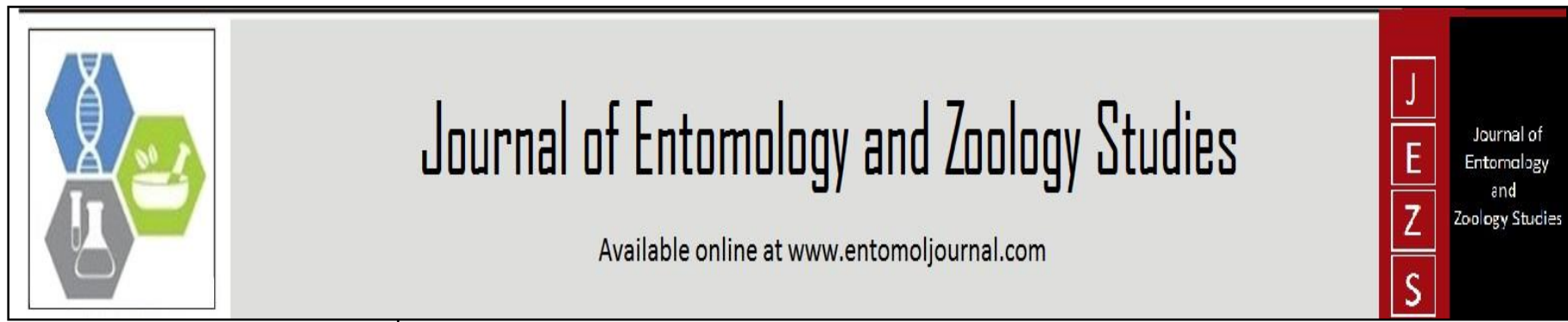

E-ISSN: 2320-7078

P-ISSN: 2349-6800

www.entomoljournal.com

JEZS 2021; 9(2): 710-713

(C) $2021 \mathrm{JEZS}$

Received: 02-01-2021

Accepted: 25-02-2021

\section{AR Ratnaparkhi}

Ph.D., Scholar, Department of Animal Reproduction, Gynaecology and Obstetrics. Post Graduate

Institute of Veterinary and Animal

Sciences, Akola, Maharashtra, India

SG Deshmukh

Assistant Professor, Department of Animal Reproduction, Gynaecology and Obstetrics. Post Graduate

Institute of Veterinary and Animal Sciences, Akola, Maharashtra, India

\section{CH Pawshe}

Professor and Head, Department of Animal Reproduction, Gynaecology and Obstetrics Post Graduate

Institute of Veterinary and Animal Sciences, Akola, Maharashtra, India

\section{Ingawale}

Assistant Professor, Department of Animal Reproduction, Gynaecology and Obstetrics Post Graduate

Institute of Veterinary and Animal

Sciences, Akola, Maharashtra, India

MG Thorat

Professor and Head, Department of Veterinary Surgery and Radiology,

Post Graduate Institute of Veterinary and Animal Sciences, Akola,

Maharashtra, India

\section{SV Kuralkar}

Professor and Head, Department of Animal Genetics and Breeding Post Graduate Institute of Veterinary and Animal Sciences, Akola, Maharashtra, India

MS Patil

Assistant Professor, Department of Animal Reproduction, Gynaecology and Obstetrics. Nagpur Veterinary College, Nagpur, Maharashtra, India VB Kale

Ph.D. Scholar, Department of Animal Reproduction, Gynaecology and Obstetrics. Post Graduate Institute of Veterinary and Animal Sciences, Akola, Maharashtra, India

SD Chepte

Assistant Professor, Department of Veterinary Surgery \& Radiology. College of Veterinary and Animal Sciences, Parbhani

Corresponding Author: SG Deshmukh

Assistant Professor, Department of Animal Reproduction, Gynaecology and Obstetrics. Post Graduate

Institute of Veterinary and Animal Sciences, Akola, Maharashtra, India

\section{Effect of dietary supplementation of crushed soybean and flaxseed on ovarian response in postpartum crossbred dairy cows}

\author{
AR Ratnaparkhi, SG Deshmukh, CH Pawshe, MV Ingawale, MG Thorat, \\ SV Kuralkar, MS Patil, VB Kale and SD Chepte
}

DOI: https://doi.org/10.22271/j.ento.2021.v9.i2j.8554

\begin{abstract}
The effect of dietary supplementation of crushed soybean and flaxseed on ovarian function in postpartum crossbred dairy cows was studied. Total 20 postpartum normally calved cows from $2^{\text {nd }}$ to $4^{\text {th }}$ lactation were randomly divided into two equal groups. In addition to routine feed, cows from group $\mathrm{T}_{1}$ were fed with dietary supplementation of crushed soybean @ $10 \%$ of DM requirement from the day of calving to day 50 postpartum and thereafter continuation with curshed Flaxseed @ 15\% of DM requirement of animal from day 51 to day 85 postpartum respectively, whereas cows from Group $\mathrm{T}_{2}$ was considered as control and supplemented with routine feed. All the animals from both groups were synchronized on day 60 postpartum with Ovsynch protocol. The Follicular dynamic study with the help of USG was undertaken at every 24 hrs interval before the first injection of GnRH of Ovsynch protocol and during Ovsynch protocol (Day 0 to Day 9) of synchronization. It was observed that mean number of class II follicles and total number of follicles were significantly increased in $\mathrm{T}_{1}$ group as compared to $\mathrm{T} 2$ group, whereas the mean number of class I and class III follicles did not differ significantly in T1 and T2 groups on day 0. During the synchronization period the mean number of class I, class II, total numbers of follicles and preovulatory follicles size were significantly larger in T1 as compared to T2 groups. The present research findings concluded that the dietary supplementation of crushed soybean and flaxseed showed significant increase in class I, class II, total number of follicles and size of preovulatory follicle in crossbred cows as compare to control group.
\end{abstract}

Keywords: Follicular dynamics, flaxseed, soybean, postpartum cows, ovsynch protocol

\section{Introduction}

Reproductive inefficiency is a major economic problem in dairy production, particularly during the phase of negative energy balance that occurs in early lactation. One way of improving energy status and thereby reproductive performance is to increase the energy density of the diet with fat supplementation and the reproductive performance is enhanced by dietary fat independent of energy status (Staples et al., 1998) ${ }^{[16]}$. It is known that, cows fed supplemental fat may experience improved energy balance and begin to cycle sooner because of enhanced follicular growth and development (Grummer and Carroll, 1991). Dirandeh et al., (2013) ${ }^{[3]}$ stated that, feeding a source of omega 6 fatty acid can be a strategy to improve uterine health after calving, although the source of omega 3 fatty acids such as Linseed should be fed after uterine involution to decrease PGF2 $\alpha$ secretion. The main source of omega- 6 fatty acid is dietary linoleic acid (C18:2n-6), which inter alia is the precursor of the dieonic (2series) prostaglandins, such as $\mathrm{PGF}_{2} \alpha$ (Abayasekara and Wathes, 1999) ${ }^{[14]}$. Beside, excess linoleic acid can be converted to a shunt metabolite, eicosadienoic acid (C20:2), rather than to arachidonic acid (Kaduce et al.,1982) Flaxseed and soybean is an excellent source of fat and polyunsaturated fatty acid (PUFA), but it is not commonly fed to cattle. PUFAs particularly the linolenic acid (Omega 3) and the linoleic acid (Omega 6) have gained attention owing to their classification as essential fatty acids. In cattle, dietary supplementation with various long chain PUFAs (both n-3 and n-6) induced changes in several aspects of folliculogenesis including both an increase in total follicular number and the size of the dominant or preovulatory follicle (Ambrose et al., 2006) ${ }^{[1]}$. Higher fertility was reported in cows ovulating larger follicles even without an increase in progesterone concentration in the subsequent luteal phase (Peter and Pursley, 2003) ${ }^{[11]}$. The $20 \%$ increase in the first service conception rate in soybean fed animals was observed by Howlet et al., (2003). 
Some previous studies reported an increase in the number of medium-sized follicles after administration of PUFAs in the form of crushed soybean, soybean oil or rice bran (Dirandeh et al., 2013, Lammoglia et al., 1996 and Thomas et al., 1997) $[3,10,18]$. Dietary fat may enhance follicular development via metabolic hormones that act either at the ovarian level or on the central nervous system to stimulate GnRH secretion; thereby increased basal LH concentrations (Thomas and Williams, 1996) ${ }^{[17]}$. As there is scanty literature available on the effect of dietary supplementation of crushed soybean and flaxseed on ovarian function, the present study was conducted with the aim to investigation the influence of dietary crushed soybean and flaxseed on ovarian function in postpartum crossbred cows.

\section{Materials and Methods}

\subsection{Selection and treatment of animals}

For the present study normally calved postpartum, pluriparus crossbred dairy cows having normal reproductive cycle were selected from the Instructional Livestock Farm Complex of Dr. Panjabrao Deshmukh Krishi Vidyapeeth, Akola. The cows were subjected to gynaecological examination using transrectal ultrasonography before inclusion in the study. The cows diagnosed with any apparent pathological condition of the reproductive tract were not included

A total of twenty postpartum cows were selected and divided into two groups $(n=10)$ as follows. In the present study; experiment was conducted to determine the effect of roasted crushed soyabean and flaxseed on ovarian activity. The selected 20 cows were equally divided in to two groups i.e. $\mathrm{n}=10$ (Treatment group T1 and control group T2). The cows were fed daily as per the routine practices along with the mineral mixture to meet the maintenance and production requirements. The routine feed comprised of $2 / 3^{\text {rd }}$ roughages $\left(2 / 3^{\text {rd }}\right.$ Kutti $+1 / 3^{\text {rd }}$ Grass $)$ and $1 / 3^{\text {rd }}$ concentrates. The dry matter consumption was estimated @ $2.5 \mathrm{~kg} / 100 \mathrm{~kg}$ body weight. The animals were provided clean drinking water for 24 hours. The roasted crushed soybean was supplemented @ $10 \%$ of DM $(300 \mathrm{~g} / 100 \mathrm{~kg}$ of body weight/animal/day; as per Dirandeh et al., $2013^{[3]}$ as a supplement over and above the feed which was routinely fed, on a dry matter basis from the day 0 Postpartum (PP) today 50 and thereafter, supplementation of crushed flaxseed @ 15\% DM (300 g/100 $\mathrm{kg}$ of body weight/animal/day as per Deshmukh et al., (2017) [2] was started from day $51 \mathrm{PP}$ and was continued up to 85 days postpartum. Whereas Group II control (T2) animals were fed routinely with regular diet/feed.

\subsection{Estrus synchronization \& follicular dynamics}

All the cows from two treatment groups were subjected to an Ovsynch synchronization protocol on day 60 postpartum treated with Inj. Buserelin acetate $10 \mu \mathrm{g} \mathrm{I} / \mathrm{m}$ on day 0 , Inj. Cloprostenol sodium $500 \mu \mathrm{g}$ on day 7 and Inj. Buserelin acetate $10 \mu \mathrm{g} \mathrm{I} / \mathrm{m}$ on day 9 , respectively. A follicular study was carried out before onset (day 0) and with 24 hrs intervals during Ovsynch protocol of estrus synchronization (day 0-9). Ultrasonography was carried out transrectally with a lineararray 7.5 MHZ probe. The size and number of follicles $>3$ $\mathrm{mm}$ were recorded on detail follicular maps. Follicles were grouped into three classes for analysis: class 1-small follicles (3.0 to $4.9 \mathrm{~mm}$ ), class 2-medium follicles (5.0 to $9.9 \mathrm{~mm}$ ) and class 3-large follicles (>10 mm). The growth rate, atresia rate, day of emergence of the new follicle, day of deviation of follicle, diameter of deviated follicles, at the time of deviation and diameter of preovulatory follicles were studied. Timed artificial insemination (TAI) was carried out at 16-24 hrs after the second GnRH injection. The approval of "Institutional Ethics Committee for Veterinary Clinical Research (IECVCR) was obtained vide Resolution no. 02/07 of 2019 The data collected on various parameters were analysed by Student $\mathrm{T}$ test using WASP (Web Agri. Stat Package) developed by ICAR.

\section{Result and Discussion \\ 3.1 Ovarian response in different groups}

3.2. Ovarian response on day 0 before initiation of Ovsynch protocol.

The mean number of Class II follicles and a total number of follicles were significantly more in $\mathrm{T}_{1}$ group on day 0 i.e. before initiation of Ovsynch protocol as compared to the $\mathrm{T}_{2}$ group, whereas the mean number of Class I and Class III were at par in $\mathrm{T}_{1}$ and $\mathrm{T}_{2}$ groups (Table 1 ).

Table 1: The total number of different class of follicles before onset of Ovsynch protocol for synchronization (on day 0) in different groups of postpartum crossbred dairy cows

\begin{tabular}{|c|c|c|c|}
\hline \multirow{2}{*}{ Class of Follicle } & \multicolumn{2}{|c|}{ Total number different class of follicles } & \multirow{2}{*}{ ' $\mathbf{T}^{\text {' }}$ Statistics } \\
\cline { 2 - 3 } & $\mathbf{T}_{\mathbf{1}}$ & $\mathbf{T}_{\mathbf{2}}$ & \\
\hline Class I (Small) & $1.7 \pm 0.21$ & $1.3 \pm 0.15$ & NS (1.524) \\
\hline Class II (Medium) & $3.5 \pm 0.21^{\mathrm{a}}$ & $2.0 \pm 0.21^{\mathrm{b}}$ & 4.881 \\
\hline Class III (Large) & $0.5 \pm 0.22$ & $0.5 \pm 0.16$ & 0.000 \\
\hline Total number of follicles & $5.7 \pm 0.15^{\mathrm{a}}$ & $3.8 \pm 0.2^{\mathrm{b}}$ & 7.550 \\
\hline
\end{tabular}

$\mathrm{T}_{1}$ crushed Soybean $\&$ flaxseed, $\mathrm{T}_{2}$ control group. $\mathrm{NS}=$ non-significant.

The mean bearing different superscripts in a row, differs significantly.

This significant increase in class II and total number of follicles in supplemented group might be due to dietary fat that may have enhanced follicular development via metabolic hormones that act on the central nervous system to stimulate GnRH secretion and thereby increased basal LH concentrations. Another way in which dietary fat may affect follicular development is through metabolic hormones acting at the ovarian level. Thomas and Williams, (1996) ${ }^{[17]}$ found that follicular development, along with plasma insulin and follicular IGF-2 concentrations, was enhanced by soybean oil.
Supplementation of soybean was effective in increasing the number of medium sized follicles compared to a saturated fat or a highly unsaturated fat (fish oil) supplement and this was associated with higher serum insulin and increased granulose cell proliferation (Poretsky and Kalin, 1987) ${ }^{[13]}$. In the present study, the significant increase in class II and total number of follicle on day 0 in supplemented group is in accordance with Deshmukh et al. (2017) ${ }^{[2]}$ who reported significant increase in class II and total number of follicles after supplementation of soybean oil and flaxseed in post partum cows. The mean total number of class I follicles showed non significant difference between the supplemented and non supplemented groups. On 
the contrary Deshmukh et al. (2017) ${ }^{[2]}$ reported a significant increase in class I follicles in the supplemented group.

\subsection{Ovarian response during synchronization period}

The mean number of Class I, class II and total number of follicles during synchronization period (0-9 day) in group $T_{1}$ is significantly higher as compared to the control group i.e. $\mathrm{T}_{2}$. Whereas the mean total number of Class III follicles were at par $\mathrm{T}_{1}$ and $\mathrm{T}_{2}$ groups (Table 2 )

Table 2: The total number of different classes of follicles on day 0-9 in different groups of postpartum crossbred dairy cows during Ovsynch protocol

\begin{tabular}{|c|c|c|c|}
\hline \multirow{2}{*}{ Class of Follicle } & \multicolumn{2}{|c|}{ Total number of different class of follicles } & \multirow{2}{*}{ 'T' $\mathbf{T}^{\text {Satistics }}$} \\
\cline { 2 - 3 } & $\mathbf{T}_{\mathbf{1}}$ & $\mathbf{T}_{\mathbf{3}}$ & \\
\hline Class I (Small) & $3.35 \pm 0.08^{\mathrm{a}}$ & $2.27 \pm 0.07^{\mathrm{b}}$ & 9.571 \\
\hline Class II (Medium) & $2.6 \pm 0.08^{\mathrm{a}}$ & $1.33 \pm 0.07^{\mathrm{b}}$ & 9.932 \\
\hline Class III (Large) & $1.02 \pm 0.03$ & $1.00 \pm 0.02$ & $\mathrm{NS}(0.480)$ \\
\hline Total number of follicles & $6.82 \pm 0.15^{\mathrm{a}}$ & $4.60 \pm 0.11^{\mathrm{b}}$ & 11.601 \\
\hline
\end{tabular}

T1 crushed Soyabean and flaxseed, T2 control group.

The mean bearing different superscripts in a row, differs significantly.

These findings regarding the significant increase in Class I, class II (medium) follicles and total number of follicles were in close accordance with Deshmukh et al. (2017) ${ }^{[2]}$ with feeding soybean oil and crushed flaxseed, Ghasemzadeh $e t$ al. (2011) ${ }^{[5]}$ with feeding fish oil and soybean oil. Ponter et al. (2006) ${ }^{[12]}$ recorded increase in small size follicles whereas medium size follicles was in accordance with others (Thomas et al. 1997; Robinson et al. 2002; Kassa et al. 2002 and Gulliver et al. 2012) [18, 14, 9, 7] who reported increase in medium size follicles with feeding different source of linolenic and linoleic acid. Ulfina et al. (2015) ${ }^{[20]}$ observed the total number of follicles tended to be $(p=0.08)$ higher for the flaxseed group as compared to the other groups.

\subsection{Follicular dynamic during estrus synchronization in different groups}

The mean growth rate and day of emergence of follicle in $T_{1}$ group were significantly higher as compared to $T_{2}$ group during synchronization period. The rate of atresia of follicles, the mean day of deviation, mean diameter of deviated follicles and mean diameter of the subordinate follicle at the time of deviation did not differ significantly between the groups. The mean preovulatory follicle diameter was significantly larger in $\mathrm{T}_{1}$ group as compared to $\mathrm{T}_{2}$ group (Table 3 ).

Table 3: The mean follicular dynamics status in both groups of crossbred dairy cows during synchronization period

\begin{tabular}{|c|c|c|c|c|}
\hline Sr. No. & Parameters & $\mathbf{T}_{1}$ & $\mathbf{T}_{3}$ & 'T' Statistics \\
\hline 1 & Mean growth rate (mm) & $1.27 \pm 0.08^{\mathrm{a}}$ & $0.83 \pm 0.05^{b}$ & 4.428 \\
\hline 2 & Mean atresia rate $(\mathrm{mm})$ & $0.65 \pm 0.01$ & $0.69 \pm 0.02$ & NS (-1.459) \\
\hline 3 & Mean day of emergence of new follicle (days) & $2.0 \pm 0.10^{\mathrm{a}}$ & $2.55 \pm 0.13^{b}$ & -3.161 \\
\hline 4 & Mean day of deviation (days) & $3.0 \pm 0.25$ & $3.3 \pm 0.33$ & NS (-0.709) \\
\hline 5 & Mean diameter of deviated follicle $(\mathrm{mm})$ & $8.68 \pm 0.06$ & $8.67 \pm 0.03$ & NS $(0.140)$ \\
\hline 6 & Mean diameter of largest subordinate follicle at the time of deviation $(\mathrm{mm})$ & $7.32 \pm 0.05$ & $7.36 \pm 0.04$ & NS (-0.548) \\
\hline 7 & Mean diameter of pre ovulatory follicle $(\mathrm{mm})$ & $16.54 \pm 0.26^{\mathrm{a}}$ & $13.62 \pm 0.17^{b}$ & 9.113 \\
\hline
\end{tabular}

T1 crushed soyabean and flaxseed, T2 control group. NS = non-significant.

The mean bearing different superscripts in a row, differs significantly.

The present finding regarding mean growth rate $(\mathrm{mm} /$ day) of ovulatory follicle, mean day of emergence of new follicle was in accordance with Deshmukh et al. (2017) ${ }^{[2]}$ who reported a significant difference in growth rate and the mean day of emergence of new follicle with supplementation of soybean oil and crushed flaxseed as compared to no fat supplementation group. Similarly, the mean day of emergence of new follicle after injection of first GnRH was in close agreement with Twagiramunga et al. (1995) ${ }^{[19]}$. The atresia rate $(\mathrm{mm} /$ day) of reducing subordinate follicle recorded in present study were in accordance with Gaur and Purohit (2007) ${ }^{[4]}$ and Henrique et al. (2000) ${ }^{[8]}$. On the contrary to the present finding, Deshmukh et al. (2017) ${ }^{[2]}$ reported significant difference in atresia rate in soybean oil fed cows as compared to no fat fed cows which is in accordance with the present findings. The mean day of deviation of dominant follicle after GnRH injection recorded was in agreement with Deshmukh et al. (2017) ${ }^{[2]}$ and Segwagwe et al. (2006) ${ }^{[15]}$. The mean diameter of deviated and subordinate follicle on the day of deviation recorded was in similarity with Deshmukh et al. (2017) ${ }^{[2]}$ and Ginther et al. (2000) ${ }^{[6]}$ who reported the mean diameter of deviated and subordinate follicle on the day of deviation was $8.65,7.32$ and $8.5,7.7 \mathrm{~mm}$, respectively. The mean diameter of preovulatory follicle recorded in the present study was in close agreement with Deshmukh et al. (2017) ${ }^{[2]}$ who reported significant increase in preovulatory follicle size of cows supplemented with soybean oil and crushed flaxseed group as compared to no fat fed cows. Similarly, Ghasemzadeh et al. (2011) ${ }^{[5]}$ recorded significant increase in preovulatory follicle size in fish oil and soybean oil groups as compared to control group of cows. Similarly, Ulfina et al. (2015) ${ }^{[20]}$ observed that, the size of dominant follicle was significantly higher $(p<0.05)$ for flaxseed group as compared to control group.

\section{Conclusion}

From the study, it was concluded that dietary supplementation of roasted crushed soybean and flaxseed helps in increasing Class II, the total number of follicles and size of the preovulatory follicle in postpartum cows.

\section{Acknowledgment}

The authors are highly thankful to the Head, Department of Animal Husbandry and Dairy, Dr. PDKV, Akola for 
providing the necessary facilities and Dr. Sanjay Awaghate Regional Manager of Virbac Pvt. Ltd, Mumbai for providing the hormones in carrying out this study.

6. Conflict of Interest: All authors declare no conflict of interest.

\section{References}

1. Ambrose JD, Kastelic JP, Corbett R, Pitney PA, Petit HV, Small JA, et al, Lower pregnancy losses in lactating dairy cows fed a diet enriched in alpha-linolenic acid. $\mathbf{J}$ Dairy Sci 2006;89:3066-3074.

2. Deshmukh SG, Ingawale MV, Birade HS, Thorat MG, Kuralkar SV, Rekhate DH, et al. Effect of Dietary Supplementation of Crushed Flaxseed and Soybean oil on Ovarian Functions in Postpartum Jersey Crossbred cows. The Indian Journal of Veterinry Sciences \& Biotechnology 2017;12(3):118-123.

3. Dirandeh EA, Towhidi Z, Ansari, Pirsareei F, Adib Hashemi M, Ganjkhanlou S. et al. Plasma concentrations of PGFM and uterine and ovarian responses in early lactation dairy cows fed omega- 3 and omega- 6 fatty acids Theriogenology 2013;80(2):131-137.

4. Gaur, Mitesh, Purohit GN. Follicular dynamics in Rathi cattle. Veterinarski Arciv 2007;77(2):177-186.

5. Ghasemzadeh-Nava H, Fatahnia F, Nikkhah A, Zamiri MJ. Effects of dietary polyunsaturated fatty acids on ovarian function and prostaglandin secretion in lactating dairy cows. Int. J Vet. Res 2011;5(2):129-135.

6. Ginther OJ, Bergfelt DR, Kulick LJ, Kot K. Selection of the dominant follicle in cattle: Role of estradiol. Biol. Reprod 2000;63:383-389.

7. Gulliver CE, Friend MA, King BJ, Clayton EH. The role of omega-3 polyunsaturated fatty acid in reproduction of sheep and cattle. Anim. Reprd. Sci 2012;131:9-12.

8. Henrique JMV, Ademir DeMF, Wanderlei FDS, Luis Sergio DAC. Follicular dynamics in zebu cattle. Pesq. Agropec. bras. Brasilia 2000;35(12):2501-2509.

9. Kassa T, Ambrose JD, Adams AL, Risco C, Staples CR, Thatcher MJ, et al. Effects of whole cottonseed diet and recombinant bovine somatotropin on ovarian follicular dynamics in lactating dairy cows. J Dairy Sci., 2002;85:2823-2830.

10. Lammoglia MA, Willard ST, Oldham JR, Randel RD. Effects of dietary fat and season on steroid hormonal profiles before parturition and on hormonal, cholesterol, triglycerides, follicular patterns, and postpartum reproduction in Brahman cows. J Anim. Sci 1996;74:2253-2262.

11. Peters MW, Pursley JR. Timing of final GnRH of the Ovsynch protocol affects ovulatory follicle size, subsequent luteal function, and fertility in dairy cows. Theriogenology 2003;60:1197-1204.

12. Ponter AA, Parsy AF, Sadeeb M, Grimardia B. Effect of supplement rich in linolenic acid added to the diet of postpartum dairy cows on ovarian follicle growth, and milk and plasma fatty acid composition. Reprod. Nutr. Dev 2006;46:19-29.

13. Poresty L, Kalin MF. The gonadotropic function of insulin. Endocr. Rev 1987;8:132-139.

14. Robinson RS, Pushpakumara PGA, Cheng Z, Peters AR, Abayasekara DRE, Wathes DC. Effects of dietary polyunsaturated fatty acids on ovarian and uterine function in lactating dairy cows. Reproduction
2002;124:119-131.

15. Segwagwe BVE, Macmillan KL, Mansell PD. The effect of GnRH or oestradiol injected at pro-oestrus on luteal function and follicular dynamics of the subsequent oestrous cycle in non-lactating cyclic Holstein cows. J Vet. Res 2006;73:61-70.

16. Staples CR, Burke JM, Thatcher WW. Influence of supplemental fats on reproductive tissues and performance of lactating cows. J Dairy Sci 1998;81:856871.

17. Thomas MG, Williams GL. Metabolic hormone secretion and FSH - induced superovulatory response of beef heifers fed dietary fat supplements containing predominantly saturated or polyunsaturated fatty acids. Theriogenology 1996;45:451-458.

18. Thomas MG, Bao B, Williams GL. Dietary fats varying in their fatty acid composition differentially influence follicular growth in cows fed isoenergetic diets. J. Anim. Sci 1997; 75:2512-2519.

19. Twagiramunga H, Guiltbault LA, Dufour JJ. Synchronization of ovarian follicular waves with a gonadotropin-releasing hormone agonist to increase the precision of estrus in cattle: a review. J Anim. Sci 1995;73:3141-3151.

20. Ulfina GG, Kimothi SP, Oberoi PS, Baithalu RK, Kumaresan A, Mohanty TK, et al. Modulation of postpartum reproductive performance in dairy cows through supplementation of long- or short-chain fatty acids during transition period. J Anim. Phy. and Anim. Nutri. 2015, 19. 